\title{
Vascular Dysfunction in Pneumocystis-Associated Pulmonary Hypertension Is Related to Endothelin Response and Adrenomedullin Concentration
}

\author{
Dan W. Siemsen, Erin Dobrinen, Soo Han, Kari Chiocchi, Nicole Meissner, and Steve D. Swain
}

From the Department of Microbiology and Immunology, Montana State University, Bozeman, Montana

\author{
Accepted for publication \\ October 22, 2015. \\ Address correspondence to \\ Steve D. Swain, Ph.D., Depart- \\ ment of Microbiology and \\ Immunology, Montana State \\ University, Bozeman, \\ MT 59717. E-mail: steve. \\ swain@montana.edu.
}

\begin{abstract}
Pulmonary hypertension subsequent to an infectious disease can be due to vascular structural remodeling or to functional alterations within various vascular cell types. In our previous mouse model of Pneumocystis-associated pulmonary hypertension, we found that vascular remodeling was not responsible for observed increases in right ventricular pressures. Here, we report that the vascular dysfunction we observed could be explained by an enhanced response to endothelin-1 (20\% greater reduction in lumen diameter, $P \leq 0.05$ ), corresponding to an up-regulation of similar magnitude $(P \leq 0.05)$ of the endothelin A receptor in the lung tissue. This effect was potentially augmented by a decrease in production of the pulmonary vasodilator adrenomedullin of almost $70 \%(P \leq 0.05)$. These changes did not occur in interferon- $\gamma$ knockout mice similarly treated, which do not develop pulmonary hypertension under these circumstances. Surprisingly, we did not observe any relevant changes in the vascular endothelial nitric oxide synthase vasodilatory response, which is a common potential site of inflammatory alterations to pulmonary vascular function. Our results indicate the diverse mechanisms by which inflammatory responses to prior infections can cause functionally relevant changes in vascular responses in the lung, promoting the development of pulmonary hypertension. (Am J Pathol 2016, 186: 259-269; http://dx.doi.org/10.1016/j.ajpath.2015.10.008)
\end{abstract}

Pulmonary hypertension $(\mathrm{PH})$ is a severe and progressive condition that can develop through many pathologic mechanisms. Biopsy and postmortem samples from patients with advanced PH typically reveal relevant vascular remodeling, often in multiple vascular layers (intima, media, and adventitia). ${ }^{1-3}$ Although these lesions clearly have substantial effects on vascular resistance, it is becoming evident that changes in the functional responses of histologically normal vascular cells, that is, the ability to appropriately regulate vascular tone, are also main determinants in the development of pulmonary hypertension. ${ }^{4}$ This dysregulation of pulmonary vascular tone can occur through altered responses of vascular endothelial cells, ${ }^{5,6}$ the smooth muscle cells themselves, ${ }^{7,8}$ or via agents produced by nonvascular cells. ${ }^{9,10}$ Although a large number of vasoactive pathways could potentially be affected to cause vascular dysregulation, the commonly implicated pathway is nitric oxide (NO)-induced vasodilation, via endothelial NO synthase (eNOS). ${ }^{11,12}$ In addition, there are a number of vasoactive neuropeptides with potent effects in the pulmonary circulation: endothelin-1 (ET-1) is probably the most important vasoconstrictive agent in the lung, ${ }^{13,14}$ and adrenomedullin (ADM) is shown to be an important vasodilator. ${ }^{15,16}$ In addition to their involvement in functional dysregulation, it is also evident that alterations in some of these vasoactive pathways are mechanistically connected with subsequent vascular remodeling and perpetuation of vascular resistance. ${ }^{17-19}$ Indeed, the importance of these pathways, and the ability to make them the targets of pharmacologic intervention, has made them a central focus of therapeutic strategies. ${ }^{20,21}$

However, the upstream mechanisms by which these vascular dysregulations occur are still poorly understood.

Supported by NIH grants R01-HL096464 (S.D.S.) and IDeA Program grant GM110732, an M.J. Murdock Charitable Trust Equipment grant (2013280:MNL), and the Montana State University Agricultural Experimental Station.

Disclosures: None declared. 
Genetic mutations are implicated in some cases of idiopathic $\mathrm{PH}$, notably those in the gene for bone morphogenic protein receptor type 2 (BMPR2). ${ }^{22}$ Another, broader type of stimulus for these changes appears to be inflammation, whether nonspecific or in response to an infectious disease. ${ }^{23,24}$ Clear connections exist between many inflammatory agents, such as cytokines, chemokines, and growth factors, and the instigation of vascular remodeling. ${ }^{25-27}$ It is less clear how inflammation can induce vascular dysregulation in the absence of vascular remodeling, although several mechanisms are proposed. For eNOS, this includes changes in protein expression, ${ }^{28}$ impairment of enzymatic activity by molecular uncoupling, ${ }^{29}$ and inhibition of eNOS by asymmetric dimethylarginine (ADMA). ${ }^{30}$ In the ET-1 system, up-regulation of both ET-1 itself ${ }^{31}$ and ET-1 receptors ${ }^{32}$ was reported in response to inflammatory mediators.

We have previously described persistent $\mathrm{PH}$ as sequel to recently cleared Pneumocystis infection in the context of transient CD4 T-cell depletion in mice. ${ }^{33}$ Although minor remodeling of the pulmonary vascular adventitia was present in these mice, it was not necessary for the development of $\mathrm{PH}$; however, resurgent CD4 cells and the inflammatory cytokine interferon (IFN)- $\gamma$ were required. ${ }^{34}$ In light of these observations, we examined whether there were persistent forms of dysregulation in the eNOS, ET-1, and ADM responses in the lungs of these mice, distinct from remodeling events, which could contribute to the PH that we observed. Although we found several inflammation-induced alterations to vasoactive pathways, surprisingly, no substantial changes to vascular NOS responses was found. However, we do report here substantial enhancement of the vasoconstrictor response to ET-1 and marked reduction in ADM production in mice with Pneumocystisassociated PH which together could account for the observed increase in pulmonary vasculature pressure. These observations indicate how inflammatory responses to an acute respiratory disease may initiate a chronic debilitating condition.

\section{Materials and Methods}

\section{Mice}

Most of the mice used in this study were raised in the animal research facility at Montana State University, from stock obtained from The Jackson Laboratory (Bar Harbor, ME). IFN- $\gamma$ knockout mice were from JAX stock number 002286 and were on a BALB/c background, as were severe combined immunodeficient mice originally obtained from Charles River Laboratories (no. 236; Wilmington, MA). Some BALB/c mice were used directly after purchase from Charles River Laboratories. Mice were housed in highefficiency particulate arresting-filtered ventilator cages, with a 12:12 photoperiod, acidified drinking water, and autoclaved mouse chow ad libitum. Experiments were begun with mice 6 to 8 weeks of age. Because estrogens are reported to have complex effects on the development of $\mathrm{PH},{ }^{35}$ we used exclusively male mice.



Figure 1 The preferred small artery profiles (arrow) for precision cut lung slices measurement are near clusters of $A D s$. $A D$, alveolar duct.

\section{Pneumocystis Culture and Infection}

Pneumocystis murina was maintained in severe combined immunodeficient mice by serial colonization. Pneumocystis was then obtained by homogenization of the lungs of infected source mice and enumerated by microscopic counts of Pneumocystis nuclei. Isoflurane anesthetized experimental mice were administered $10^{7}$ Pneumocystis via intratracheal delivery, as previously described. ${ }^{36}$ Mice were given short-term depletions (STDs) of CD4 T-cell populations by i.p. injections of $300 \mu \mathrm{g}$ of the antibody GK1.5 at days $-3,0,3,7$, relative to the day of infection. With this procedure, CD4 cells return at 18 to 24 days after infection and initiate clearance of the Pneumocystis infection. ${ }^{33}$ Wild-type BALB/c mice treated in this way are referred to as BALB-STD mice, whereas IFN- $\gamma$ knockout mice in this procedure are referred to as IFN- $\gamma-\mathrm{STD}$ mice. Experiments described in the next section were performed at 35 to 40 days after infection, when $\mathrm{PH}$ is persistent, and the Pneumocystis is almost entirely cleared. ${ }^{34}$ Control animals are untreated age- and sex-matched BALB/c mice.

\section{Hemodynamic Measurements}

Right ventricular pressure, and relative right ventricular mass were measured via trans-thoracic puncture and direct weighing, as previously described. ${ }^{33}$

\section{Tissue Collection}

Tissue samples were obtained from mice deeply anesthetized with pentobarbital and euthanized by exsanguination. In some cases, bronchoalveolar lavage was performed with $3 \mathrm{~mL}$ of phosphate-buffered saline with $3 \mathrm{mmol} / \mathrm{L}$ EDTA. ${ }^{36}$ Lungs were removed and immediately homogenized in $10 \mathrm{~mL}$ of ice-cold phosphate-buffered saline with $3 \mathrm{mmol} / \mathrm{L}$ EDTA, protease inhibitor cocktail (P8340; Sigma-Aldrich, St. Louis, MO), and 

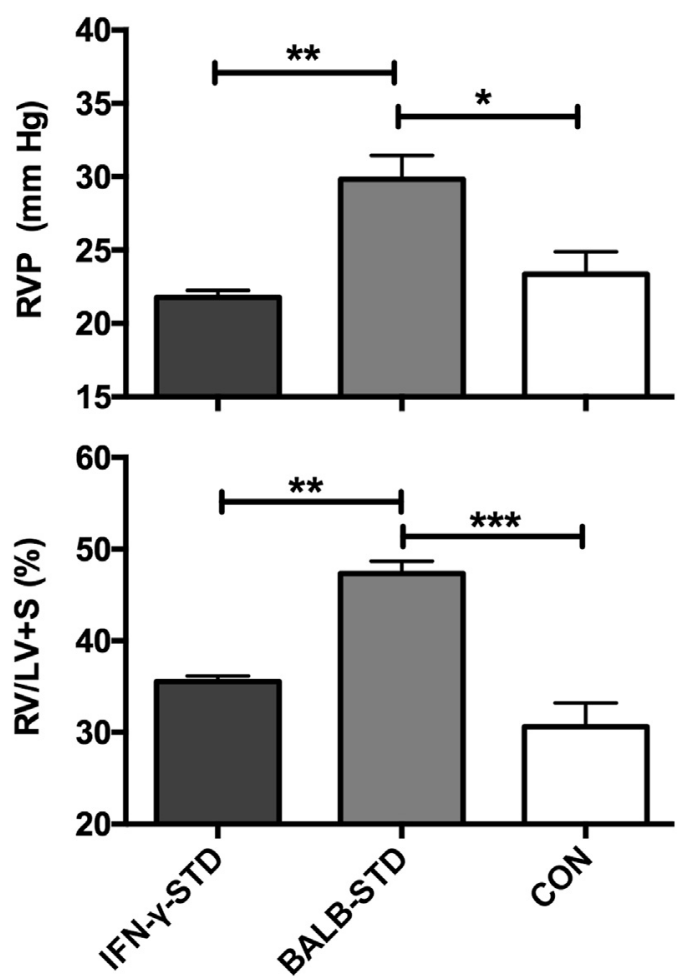

Figure 2 Pulmonary hypertension manifests as elevated RVP and hypertrophy of the right ventricle (RV/LV+S) occurs in BALB-STD mice but not IFN- $\gamma$-STD mice. Data are expressed as means \pm SEM. $n=5$ mice in two independent experiments. ${ }^{*} P \leq 0.05,{ }^{*} P \leq 0.01$, and ${ }^{* * *} P \leq 0.001$ versus BALB-STD mice. CON, control; IFN, interferon; RV/LV $+S$, right ventricular mass as a proportion of the left ventricular plus septal mass; RVP, right ventricular pressure; STD, short-term depletion.

phosphatase inhibitor cocktail (P5726; Sigma-Aldrich), using an Omni THQ homgenizer (Omni-International, Kennesaw, $\mathrm{GA})$. Aliquots were quick frozen over liquid nitrogen and kept at $-80^{\circ} \mathrm{C}$ until needed. Homogenate samples were used as in arginase assays and enzyme-linked immunosorbent assays (ELISAs), with appropriate dilutions. For Western blot analysis, samples were thawed, mixed with $2 \times$ SDS sample buffer, and boiled for 5 minutes. When membrane proteins were the target of analysis, a $2 \%$ octyl glucoside extract was made by adding the appropriate volume of a $10 \times$ octyl glucoside stock to the thawed extract and incubating on ice for 10 minutes with frequent mixing on a vortex, after which $2 \times$ SDS buffer was added, and the samples were boiled for 5 minutes. Equal volumes of each sample were loaded onto the gels, representing equal fractions of the entire lung. Previously infected mice have residual inflammation ${ }^{33}$ and resulting increased total lung mass compared with controls, so normalization to nonspecific housekeeping proteins (present in all cells) was not performed.

\section{PCLS Procedures}

Precision cut lung slices (PCLSs) were obtained with modifications of published methods. ${ }^{37-39}$ Briefly, after euthanization, skin and rib cage were removed to expose the lungs, and a small slit was made in the trachea. A Y cannula (BD Saf-T-Intima; Becton Dickinson, Sandy, UT) was inserted into the slit and tied with a small suture, a 3-mL syringe with $2 \mathrm{~mL}$ of air was attached to one port, and through the second port 1 to $1.5 \mathrm{~mL}$ of $2 \%$ agarose in phosphate-buffered saline at $35^{\circ} \mathrm{C}$ was instilled into the lung. This was followed by injection of $0.35 \mathrm{~mL}$ of air, then a second suture was tied below the cannula, heart and lungs were removed en bloc and put into cold Dulbecco's phosphate-buffered saline for 30 minutes to solidify the agarose. Vibratome sections of $200 \mu \mathrm{m}$ were cut from left, superior, and inferior lobes of the lung and put into 12-well plates with modified Dulbecco's modified Eagle's medium (high glucose with sodium glutamate, without Phenol Red, plus $25 \mathrm{mmol} / \mathrm{L}$ sodium pyruvate and $15 \mathrm{mmol} / \mathrm{L}$ HEPES). Sections were kept overnight in a $37^{\circ} \mathrm{C} 5 \% \mathrm{CO}_{2}$ incubator, with two to three changes of media the next 5 hours. Viability of the sections was verified the next day by motion of cilia in larger airways.

Viable sections were placed in a modified 35-mm Petri dish with optical glass bottom (MatTek, Ashland, MA) inserted into a $37^{\circ} \mathrm{C}$ microincubator (Bioscience Tools, San Diego, CA) within the stage of a Nikon TE300 inverted microscope (Nikon Instruments, Melville, NY). Media kept at $37^{\circ} \mathrm{C}$ (with or without vasoactive agents) were perfused through ports in the dish at $0.8 \mathrm{~mL} / \mathrm{min}$. Appropriate arterial profiles (identified by a thicker smooth muscle media layer) were of two types: smaller arteries (diameter, 13 to $36 \mu \mathrm{m}$ ) at the level of the alveolar ducts, ${ }^{38}$ which accounted for approximately $80 \%$ of the profiles analyzed (Figure 1) and
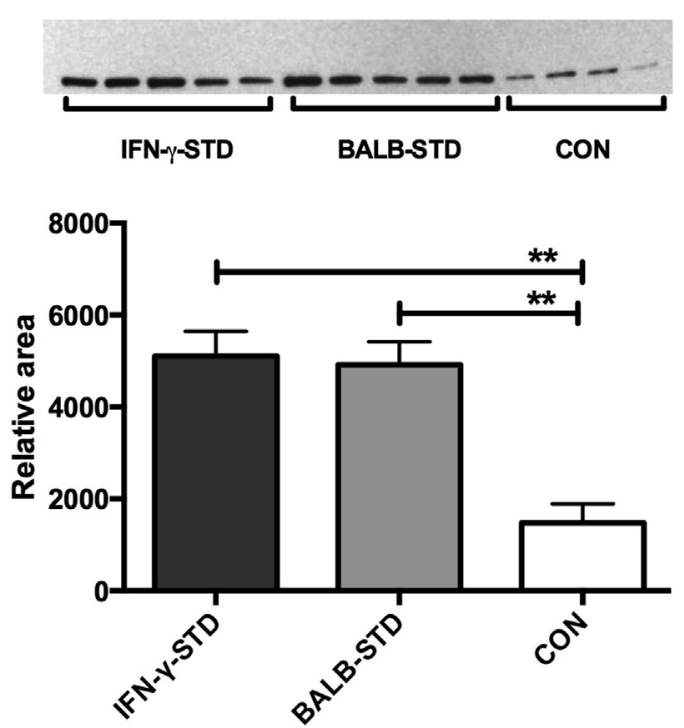

Figure 3 eNOS levels are increased in both BALB-STD and IFN- $\gamma$-STD mice. Densitometric review of Western blot analyses of the eNOS protein in total lung homogenates show significant increases in the BALB-STD and IFN- $\gamma$-STD groups compared with controls. Data are expressed as means \pm SEM. $n=5$ (4 for control) in two independent experiments. ${ }^{* *} P \leq 0.01$ versus controls. CON, control; eNOS, endothelial nitric oxide synthase; IFN, interferon; STD, short-term depletion. 



Figure 4 eNOS-mediated vasodilation of small pulmonary arteries is not impaired by inflammation in short-term CD4-depleted, Pneumocystisinfected mice. A-D: Arterial response in precision cut lung slice measurements of a representative live lung section. Lumen of resting artery (A), lumen contracted to near 50\% original area after U46619 treatment (B), lumen restored to near original size after acetylcholine-mediated eNOS activation (C), and little to no increased dilation after final treatment with SNP (D). E-G: U46619 contraction is enhanced in both BALB-STD and IFN- $\gamma$-STD mice (E), but eNOS activation returns lumen area to the same magnitude as in control mice (F), although this requires significantly greater dilation in both BALB-STD and IFN- $\gamma$-STD mice (G). H: Endothelial-independent vasodilation is not significantly different among the three groups of mice. Data are expressed as means \pm SEM. $n=16$ to 35 profiles per group across 4 to 5 mice in three independent experiments. ${ }^{* *} P \leq 0.01,{ }^{* *} P \leq 0.001$, and ${ }^{* * * * P} \leq 0.0001$ versus controls. CON, control; eNOS, endothelial nitric oxide synthase; IFN, interferon; SNP, sodium nitroprusside; STD, short-term depletion.

larger peribronchial arteries (diameter, 27 to $76 \mu \mathrm{m}$ ) (Figure 1). Subsequent analysis showed no significant difference in the response of these two types, so they were pooled together. Each section typically had three to six measurable profiles with perpendicular planes of section. Images of each profile were taken before and after each segment of the treatment procedure with a Nikon DS-QiMc camera and Nikon Elements BR software version 3.10.

Specific treatments were modified from Faro et $\mathrm{al}^{40}$ and Wright and Churg. ${ }^{41}$ For measurement of NO response and arterial dilation after equilibration $10^{-7} \mathrm{~mol} / \mathrm{L} \mathrm{U} 46619$ (Enzo Life Sciences, Farmingdale, NY) was applied for 5 minutes to precontract vessels, followed by a 5-minute wash. After image capture, $10^{-5} \mathrm{~mol} / \mathrm{L}$ acetycholine (Tocris, Minneapolis, MN) was perfused for 8 minutes. This was followed by a wash of $5 \mathrm{~mL}$, and the final treatment of $5 \mathrm{~mL}$ of $10^{-5} \mathrm{~mol} / \mathrm{L}$ sodium nitroprusside (Sigma-Aldrich). Response to ET-1 was performed as a dose-response contraction curve of resting blood vessels. ${ }^{41}$ After equilibration, sequential doses of $10^{-11}$ to $10^{-8}$ ET-1 (Sigma-Aldrich) were applied, with 5 minutes of each dose, followed by 5 -minute washes between doses. Lumen areas in each profile before and after each treatment were measured with ImageJ software version 1.47b (NIH, Bethesda, MD; http:// imagej.nih.gov/ij). ${ }^{42}$ Typically, four to five sections from each mouse were used, and values were averaged at each treatment point per mouse, with final statistical comparisons made within the four to seven mice per group.

\section{ELISA Procedures}

ET-1 was measured in extracts from lung homogenates with the use of a commercial ELISA kit (Enzo Life Sciences), according to manufacturer's instructions, including peptide isolation on $\mathrm{C}_{18}$ Sep-Pak columns (Waters Corporation, Milford, MA). The marker of NO-modified protein 3-nitrotyrosine was measured in total lung homogenates with the use of a commercial ELISA from Abcam (no. ab116691; Cambridge, MA). ADMA, an in vivo inhibitor of eNOS, was measured in lung homogenates with the use of a commercial ELISA from MyBioSource (San Diego, CA).

\section{Western Blot Procedures}

Sample proteins were separated by PAGE with the use of $4 \%$ to $20 \%$ gradient gels (Bio-Rad, Hercules, CA). Proteins were transferred to nitrocellulose (GE Life Sciences, Piscataway, NJ) and probed with the following antibodies. Monoclonal antieNOS was from BD Transduction Laboratories (no. 610296; San Jose, CA), as was polyclonal anti-inducible NOS (iNOS; no. 610332). Polyclonal anti-ADM was from Thermo Scientific (no. PA5-24927; Waltham, MA). Polyclonal anti-endothelin 
receptor $\mathrm{A}\left(\mathrm{ET}_{\mathrm{A}} \mathrm{R}\right)$ and the control peptide to verify specificity were from Alomone Labs (no. AER-001; Jerusalem, Israel). Secondary antibodies were goat anti-mouse IgG horseradish peroxidase conjugate from Southern Biotech (no. 1031-05;
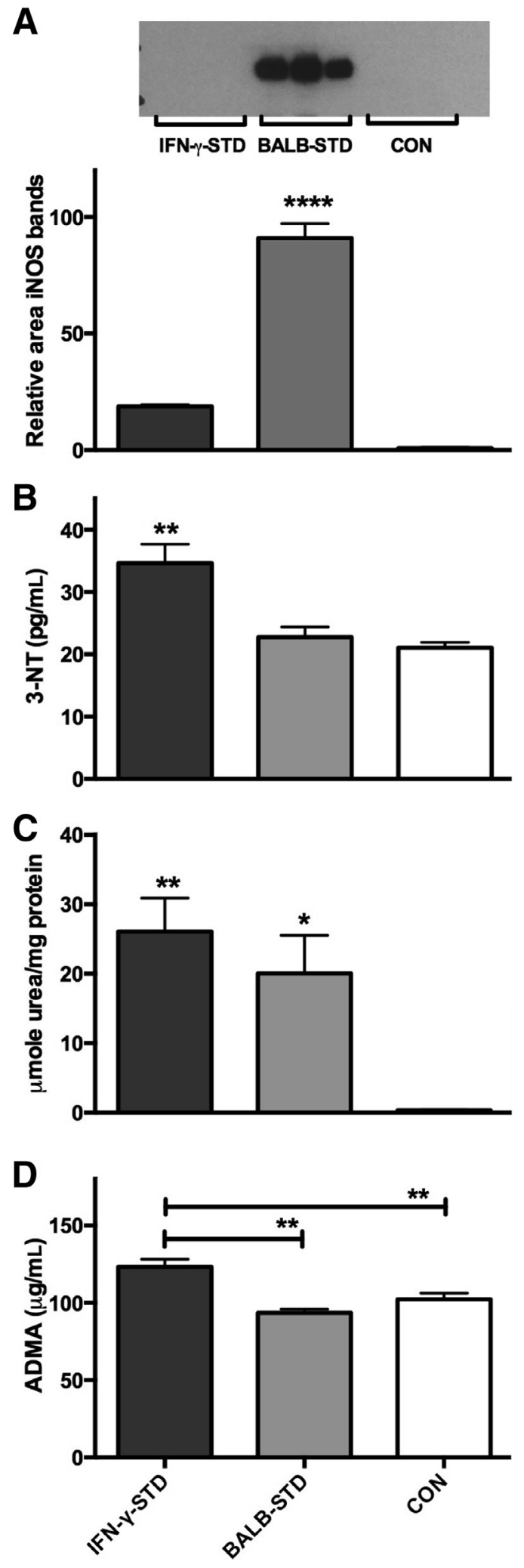

Birmingham, AL), and donkey anti-rabbit $\operatorname{IgG}$ horseradish peroxidase conjugate from BioLegend (no. 406401; San Diego, CA). Images were captured on autoradiographic film with the use of chemiluminescent substrate Pierce Super Signal West Pico (Thermo Scientific). Bands were quantified with ImageJ software. $^{42}$

\section{Arginase Assay}

Arginase activity in lung homogenates was determined with the method of Corraliza et al. ${ }^{43}$ Crude homogenates were mixed vigorously on a vortex for 30 seconds, then centrifuged for 5 minutes at $15,000 \times g$ at $4^{\circ} \mathrm{C}$. Aliquots of the supernatant fluid were then assayed according to the published procedure and compared with a standard curve of urea dilutions. Duplicate aliquots were analyzed for protein concentration with the use of the bicinchoninic acid method (Pierce Biotechnology, Rockford, IL). Arginase activity is expressed as $\mu$ mole urea produced per milligram total protein per hour.

\section{Expression Analysis}

$\mathrm{CD} 11 \mathrm{c}^{+}$pulmonary cells were isolated from lung digests as previously described. ${ }^{44}$ RNA was obtained from these cells with the use of the Qiagen (Germantown, MD) RNeasy Micro kit, and quality was verified with a RNA 6000 Nano kit (Agilent, Santa Clara, CA). Primers for iNOS (catalog no. QT00100275), arginase (catalog no. QT00134288), and glyceraldehyde-3-phosphate dehydrogenase (catalog no. QT01658692) were purchased from Qiagen. PCR was performed on an Eppendorf Mastercycler ep realplex (Hauppauge, $\mathrm{NY}$ ) with the use of a SYBER Green PCR Master mix from Thermo Fisher (catalog no. 4367659). The reaction conditions consisted of a preincubation at $95^{\circ} \mathrm{C}$ for 10 minutes, followed by 40 cycles of an amplification step that consisted of $95^{\circ} \mathrm{C}$ for 15 seconds, followed by $60^{\circ} \mathrm{C}$ for 60 seconds. Quantification was performed with the method of Livak and Schmittgen. ${ }^{45}$

\section{Statistical Analysis}

Preliminary group analysis was performed with the Numbers software program version 2.3 (Apple, Cupertino, CA). Final statistical analysis with analysis of variance

\footnotetext{
Figure 5 Potential inhibition of eNOS in BALB-STD mice may not occur. A-C: Although protein expression of iNOS in lung homogenates is strongly elevated in BALB-STD mice (A), nitrosative modification of cellular proteins is not significantly elevated in this group (B), possibly because of concomitant increase of arginase activity, which competes for the same substrate (C). D: A known tissue inhibitor of eNOS, ADMA, is also not elevated in BALB-STD mice, although it is elevated in IFN- $\gamma$-STD mice. Data are expressed as means \pm SEM. $n=5$ in two independent experiments. ${ }^{*} P \leq 0.05,{ }^{* *} P \leq 0.01$, and ${ }^{* * * *} P \leq 0.0001$ versus controls. ADMA, asymmetric dimethylarginine; CON, control; eNOS, endothelial nitric oxide synthase; IFN, interferon; iNOS, inducible nitric oxide synthase; STD, short-term depletion; 3-NT, 3-nitrotyrosine.
} 


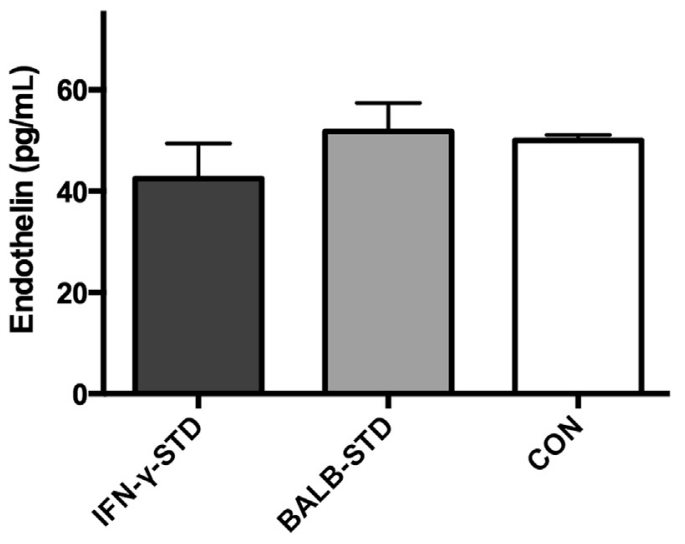

Figure 6 ET-1 concentrations are not significantly different in BALB-STD or IFN- $\gamma$-STD mice compared with controls. Samples are peptide extracts from total lung homogenates. Data are expressed as means \pm SEM. $n=5$ mice in two independent experiments. CON, control; ET-1, endothelin-1; IFN, interferon; STD, short-term depletion.

followed by Tukey's post hoc tests was performed with Prism software version of (GraphPad, San Diego, CA).

\section{Results}

Functional Responses in eNOS Are Not Involved in Pneumocystis-Associated PH Development

As reported in our previous study, ${ }^{34}$ transient depletion of CD4 cells and concomitant Pneumocystis infection resulted in persistent $\mathrm{PH}$ in wild-type mice but not in IFN- $\gamma$ knockout mice (Figure 2). Changes in eNOS protein expression were proposed as a mechanism of endothelial dysfunction; surprisingly, we found that eNOS expression was actually increased in BALB-STD mice, compared with control mice (Figure 3); however, this same increase also occurred in IFN- $\gamma$-STD mice. Because protein concentration did not support a role for eNOS in our observed vascular dysfunction, we conducted functional studies of the eNOS system in pulmonary vasculature with the use of PCLSs. This assay required initial preconstriction of the arterial profiles with the use of the thromboxane agonist U46619, followed by measurement of endothelial-dependent vasodilation (via stimulation of eNOS) by application of acetylcholine. Finally, endothelial-independent vasodilation is measured by application of the NO donor, sodium nitroprusside. We initially determined the dose of U46619 in untreated mice that would result in a $40 \%$ to $50 \%$ decrease in vascular lumen area and the subsequent dose of acetylcholine that would return the lumen size to $80 \%$ to $90 \%$ of initial area. This treatment regimen was applied to PCLSs from both BALBSTD and IFN- $\gamma$-STD mice and from control mice (Figure 4, A-D). We found that both BALB-STD and IFN$\gamma$-STD mice exhibited enhanced contractility in response to U46619, indicated by significantly greater reduction in lumen area (Figure 4E). However, when acetylcholine was subsequently applied to stimulate eNOS, vessel lumen area returned to $70 \%$ to $85 \%$ of pre-U46619 values in all three groups (Figure $4 \mathrm{~F}$ ), although this required significantly greater vasodilation, relative to the contracted vessel areas, in both groups of infected mice (Figure 4G). Finally, when sodium nitroprusside was added to the PCLSs after acetylcholine treatment, an additional vasodilatory response was found, amounting to an additional $12 \%$ to $16 \%$ of the original lumen diameter, which was not significantly different between any of the groups (Figure $4 \mathrm{H}$ ). These results suggested that both production of and response to the vasodilator endothelial NO were not significantly affected by the Pneumocystis infection, although response to vasoconstrictive agents was affected.

\section{Elevated iNOS Response or ADMA Concentrations Do Not Inhibit eNOS}

iNOS was also proposed as a modulator of vascular tone, especially in situations of IFN- $\gamma$ secretion, via production of both $\mathrm{NO}$ and superoxide, resulting in increased peroxynitrite and eNOS inactivation. As expected, iNOS protein levels were high in BALB-STD mice but not in IFN- $\gamma$-STD mice (Figure 5A). However, the elevated levels did not translate into increased nitrosative/oxidative stress. In fact, 3-nitrotyrosine, a marker of protein nitration, was significantly elevated in IFN- $\gamma$ STD mice but not in BALB-STD mice (Figure 5B). It was also surprising to find that lung arginase activity, usually inversely related to iNOS activity and a competitor for the same substrate, ${ }^{46}$ was as high or higher in BALB-STD mice than in IFN$\gamma$-STD mice (Figure 5C). Because alveolar macrophages are a main source of iNOS in lung inflammation, we measured mRNA expression of both iNOS and arginase in lung CD11 $\mathrm{c}^{+}$ cells and found increased expression of both in BALB-STD mice (data not shown), which may explain the lack of nitrosative stress. Finally, we quantified a known inhibitor of in vivo function of eNOS, ADMA, in lung homogenates, and found no difference between BALB-STD and control mice, although slightly increased concentrations were found in IFN- $\gamma$-STD mice (Figure 5D).

\section{Vasoconstriction in Response to ET-1 Is Enhanced in BALB-STD Mice}

In contrast to the vasodilatory eNOS system, the vasoconstrictive ET-1 system is important in our PH model. Concentrations of the ET-1 peptide in lung homogenates were not significantly different between any of the groups (Figure 6). As with the eNOS system, we used an ex vivo PCLS assay to measure the vasoconstrictive response to ET-1 in the three groups of mice (Figure 7). At the lowest dose of ET-1 $\left(10^{-11}\right.$ $\mathrm{mol} / \mathrm{L}$ ), a slight (approximately 10\%) increase was found in vessel lumen area in all three groups (Figure 8A). However, when ET-1 was subsequently applied at doses of $10^{-10} \mathrm{~mol} / \mathrm{L}$ to $10^{-9} \mathrm{~mol} / \mathrm{L}$, the intrapulmonary arteries in the BALB-STD group exhibited significantly greater vasoconstriction, compared with both control and IFN- $\gamma$-STD mice (Figure 8A). 

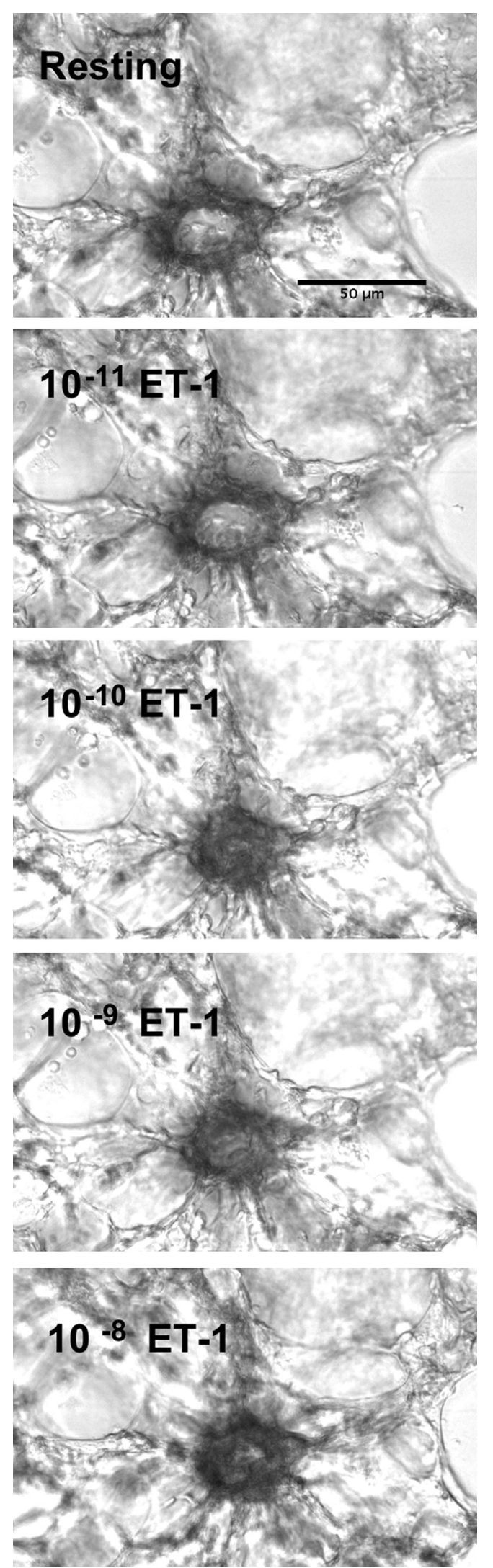

Figure 7 Small pulmonary artery profiles show increasing vasoconstriction when treated with a cumulative dose response of ET-1. Shown is a representative profile from a BALB-STD mouse precision cut lung slices sample. ET-1, endothelin-1; STD, short-term depletion.
This differential effect disappeared at the highest dose of ET-1 that we used $\left(10^{-8} \mathrm{~mol} / \mathrm{L}\right)$, at which all three groups demonstrated vasoconstriction of nearly $50 \%$ of the original lumen area (Figure 8A).

To explore possible mechanisms of this response, we examined expression levels of the $\mathrm{ET}_{\mathrm{A}} \mathrm{R}$ in lung homogenates and found a slight but significant up-regulation in the BALB-STD mice, compared with both the IFN- $\gamma$-STD and control groups (Figure 8B).

\section{Expression of the Vasodilator ADM Is Drastically Reduced in BALB-STD Mice}

Another pulmonary vasoactive agent we measured was the vasodilator ADM, which was reported in some in vitro assays to be reduced in response to IFN- $\gamma \cdot{ }^{47}$ Interestingly, we found that the $18-\mathrm{kDa}$ circulating precursor of ADM was almost absent in lung homogenates of BALB-STD mice but was abundant in both the IFN- $\gamma$-STD and control mice (Figure 9). Our Western blot analyses did not show distinct bands at the molecular weight range of the active form of $\operatorname{ADM}(6 \mathrm{kDa})$; however, this form of the molecule is known to be labile. ${ }^{48}$

\section{Discussion}

We show here that inflammatory responses to a recently cleared infectious microbe can produce alterations in the response to and/or concentration of vasoactive agents that substantially alter pulmonary vascular tone and may be instrumental in the initiation of pulmonary hypertension.

We originally hypothesized that the eNOS system of vascular regulation would be the likely candidate for impairment in BALB-STD mice. Our previous observation of the essential role of IFN- $\gamma$ suggested a mechanism similar to those seen in other disease models, in which increased NO production by iNOS (which is induced by IFN- $\gamma$ ) paradoxically results in reduced eNOS activity and inhibits vasodilation. ${ }^{49,50}$ Furthermore, in one of these studies, ${ }^{50} \mathrm{CD} 4 \mathrm{~T}$ cells were required for this response, similar to our observations of the necessity of CD4 cells for $\mathrm{PH}$ to occur. ${ }^{34}$ However, modification of eNOS function was not important in the onset of PH in BALB-STD mice. Not only did functional tests of the endothelial NO response, with the use of PCLSs, show no substantial differences in the vasodilatory response, but no evidence was found of the nitrosative effects purported to cause eNOS dysfunction in the context of elevated iNOS that we found in BALB-STD mice. This was likely because of the sequence of immune responses in these animals, in particular the unique phenotype of the pulmonary CD11c cells (alveolar macrophages and dendritic cells) in BALB-STD mice. Unlike the typical phenotype of M1 polarized cells in response to IFN- $\gamma$ secretion (one of which is the up-regulation of iNOS), these cells also exhibit aspects of an 
A

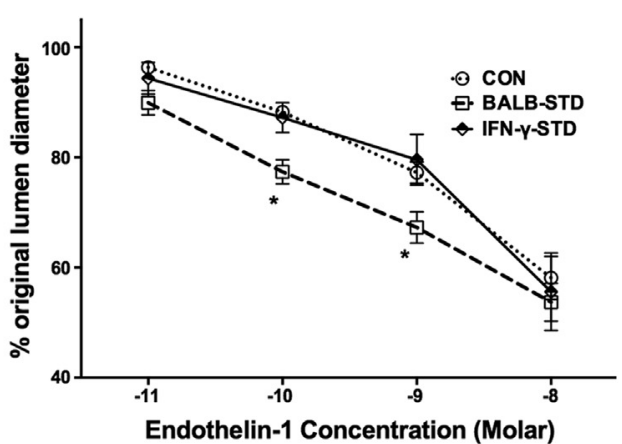

B
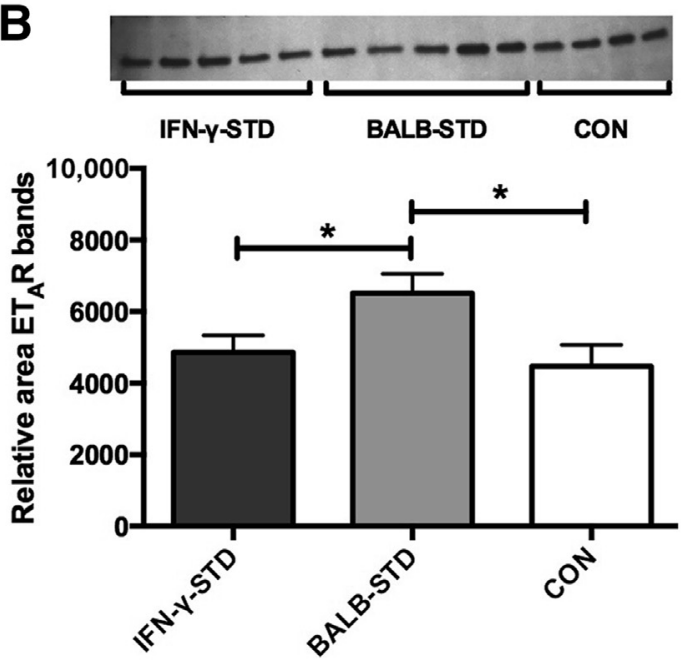

Figure 8 The response to ET-1 is enhanced in BALB-STD mice. A: Vasoconstriction in small pulmonary artery profiles in BALB-STD mice is significantly greater over the range of $10^{-10}$ to $10^{-9} \mathrm{ET}-1$. B: This coincides with a significant increase in the $\mathrm{ET}_{A} \mathrm{R}$ in BALB-STD mice total lung tissue as indicated by quantification of Western blot analysis. Data are expressed as means \pm SEM. $n=4$ to 5 (B) or $n=16$ to 35 profiles per group across 4 to 5 mice $(\mathbf{A})$ in two independent experiments. ${ }^{*} P \leq 0.05$ versus IFN- $\gamma$-STD and controls. CON, control; $E T_{A} R$, endothelin receptor $A ; E T-1$, endothelin-1; IFN, interferon; STD, short-term depletion.

M2 phenotype, including up-regulated scavenger receptor CD204 as we previously reported, ${ }^{34}$ and increased arginase expression. Indeed, this elevated arginase activity could result in reduced iNOS NO production through competition for the common substrate, arginine, ${ }^{46}$ and thus reduced nitrosative effects on tissue proteins.

In contrast to the eNOS system, functional response to ET-1 seems to be an important mechanistic component in Pneumocystis-associated PH. Inflammatory alterations in the ET-1 system were reported for several phenotypes of $\mathrm{PH} .{ }^{13}$ Increases in levels of the ET-1 peptide can occur in the lung in response to several inflammatory mediators, including tumor necrosis factor- $\alpha,{ }^{31,51,52}$ transforming growth factor- $\beta,^{53}$ and IFN- $\gamma \cdot{ }^{31,51,53}$ Unlike the latter group, we did not observe substantial increases in pulmonary ET-1 in lung samples; however, those studies were analyzed with isolated cell types with discrete stimuli, whereas ours examined total lung homogenate, taken from mice with a complex inflammatory response to a prior infectious disease. In addition, many of the in vivo effects of ET-1 result from paracrine interactions of adjacent cells, and localized concentration differences would be undetectable by our assay. Therefore, we cannot rule out completely that concentration increases of ET-1 did not have a role in the observed PH in vivo. However, our results with PCLS functional assays show that concentration increases were not necessary to demonstrate an enhanced ET-1 response in the BALB-STD mice. The up-regulation of the $\mathrm{ET}_{\mathrm{A}} \mathrm{R}$ receptor, and the associated enhanced response, which we describe here as a possible mechanism of inflammatory induced PH, was reported as a response to stressful perturbations of vascular cells. Up-regulated $\mathrm{ET}_{\mathrm{A}} \mathrm{R}$ in vascular cells occurs in response to intermittent hypoxia, ${ }^{54,55}$ ischemia-reperfusion, ${ }^{56}$ angiotensin II ${ }^{57}$ endotoxin exposure, ${ }^{32}$ environmental air pollution, ${ }^{58}$ and long-term tobacco use. ${ }^{59}$ Our observations indicate that this up-regulation can also occur as a consequence of inflammatory responses to an infectious disease.

In vivo, pulmonary vascular resistance depends on the effects of many interacting regulatory agents, although ET-1 is undoubtedly one of the most important. Our evaluation of the vasodilatory mediator ADM suggests an important role in inflammation-associated PH. Some patients with PH have elevated levels of ADM, perhaps in a compensatory vasodilatory response, ${ }^{60}$ and inhaled ADM is used with some success in PH patients. ${ }^{60}$ ADM also has potent immune modulatory actions ${ }^{61}$ and is an important human biomarker, reflecting the magnitude of several clinical conditions, including sepsis. ${ }^{62}$ That ADM is so severely down-regulated in the lungs of BALB-STD mice would appear to be maladaptive, and, in fact, may reflect another aspect of collateral damage of the immune response. IFN- $\gamma$ was shown to down-regulate ADM expression in some isolated

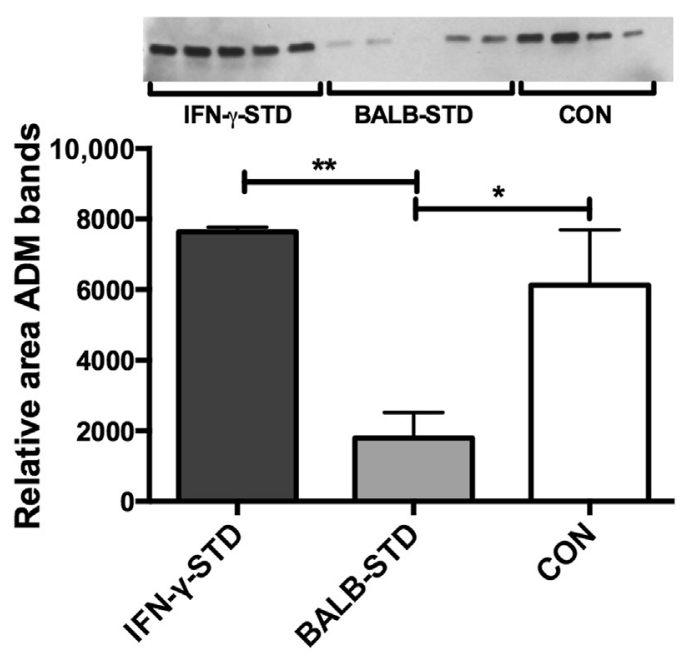

Figure 9 Expression of the vasodilator ADM is drastically reduced in BALB-STD mice. Densitometric review of Western blot analyses of the $18-\mathrm{kDa}$ $A D M$ precursor protein in total lung homogenates shows significant decrease in BALB-STD mice, compared with control and IFN- $\gamma$-STD mice. Data are expressed as means \pm SEM. $n=5$ ( 4 for control) in two independent experiments. ${ }^{*} P \leq 0.05,{ }^{*} P \leq 0.01$ versus controls. ADM, adrenomedullin; $\mathrm{CON}$, control; IFN, interferon; STD, short-term depletion. 
cell types in vitro ${ }^{47,63,64}$ yet increase it in others. ${ }^{65,66}$ Clearly, our results indicate that in vivo pulmonary ADM production can be dramatically reduced in an IFN- $\gamma-$ dependent fashion. It is likely, however, that in vivo results reflect multiple elements of the immune response, including other cytokines, and the timing and duration of the immune response. As we previously reported, pulmonary IFN- $\gamma$ levels in our experimental model are elevated for at least a 10-day period, ${ }^{34}$ and this sustained exposure may be crucial for in vivo reduction of $\mathrm{ADM}$ production. It is interesting that, although $\mathrm{ADM}$ has known biomarker and treatment uses in humans, little is known about the response of ADM in acute or chronic infectious diseases and whether this may be a predisposing factor in cases of secondary $\mathrm{PH}$, but our results would suggest this is an intriguing possibility.

Although the potential mechanisms of vascular dysregulation that we observed, enhanced response to endothelin and down-regulation of ADM, are reported in response to various perturbations, this is the first report that we are aware of in which they occur as responses to an altered immune response to an infectious disease. These results point to the importance of ongoing and prior immunologic responses to infectious agents as contributing factors in the development of $\mathrm{PH}$, which is increasingly seen as multifactorial in origin. Indeed, although it is becoming apparent that the infection history of the lung can be an important determinant of the immune responses to subsequent infections, ${ }^{67}$ it is not known whether infection history can be a lasting modifier to vasoregulatory mechanisms, but our results would suggest that this is a potential area of interest in the development of secondary $\mathrm{PH}$. As with any mouse experimental model, direct applicability to human disease is limited at this time. The conditions of our model, such as transient immunosuppression (CD4 depletion), allowing for encroachment of an opportunistic pathogen, followed by its robust elimination on CD4 resurgence, are not a common feature of human pulmonary disease. However, it does raise the question whether pulmonary diseases that involve a strong CD4 T-cell response, and/or prolonged IFN- $\gamma$, may lead to similar vascular dysfunction. A deeper understanding of the mechanisms by which immunologic perturbations may drive the types of vascular dysfunction reported here is needed.

\section{Acknowledgments}

We thank Tamara Marcotte and the staff of the MSU Animal Resources center for mouse care and breeding and Kirsten Bull, Rachelle Morton, Kyle Larsen, Teri Hoyt, Natasha Smith, Jon Gray, and Ann Harmsen for expert technical assistance.

\section{References}

1. Tuder RM, Marecki JC, Richter A, Fijalkowska I, Flores S: Pathology of pulmonary hypertension. Clin Chest Med 2007, 28:23-42
2. Caslin AW, Heath D, Madden B, Yacoub M, Gosney JR, Smith P: The histopathology of 36 cases of plexogenic pulmonary arteriopathy. Histopathology 1990, 16:9-19

3. Chazova I, Loyd JE, Zhdanov VS, Newman JH, Belenkov Y, Meyrick B: Pulmonary artery adventitial changes and venous involvement in primary pulmonary hypertension. Am J Pathol 1995, 146:389-397

4. Stenmark KR, McMurtry IF: Vascular remodeling versus vasoconstriction in chronic hypoxic pulmonary hypertension: a time for reappraisal? Circ Res 2005, 97:95-98

5. Murata T, Sato K, Hori M, Ozaki H, Karaki H: Decreased endothelial nitric-oxide synthase (eNOS) activity resulting from abnormal interaction between eNOS and its regulatory proteins in hypoxia-induced pulmonary hypertension. J Biol Chem 2002, 277 : 44085-44092

6. Yelle D, Kugathasan L, MacLaren RE, Stewart DJ: Endothelial dysfunction in pulmonary hypertension. Endothelial Dysfunction and Inflammation. Basel, Switzerland, Springer Basel, 2010, pp $81-102$

7. Moudgil R, Michelakis ED, Archer SL: The role of $\mathrm{K}+$ channels in determining pulmonary vascular tone, oxygen sensing, cell proliferation, and apoptosis: implications in hypoxic pulmonary vasoconstriction and pulmonary arterial hypertension. Microcirculation 2006, $13: 615-632$

8. Kim Y-M, Barnes EA, Alvira CM, Ying L, Reddy S, Cornfield DN: Hypoxia-inducible factor- $1 \alpha$ in pulmonary artery smooth muscle cells lowers vascular tone by decreasing myosin light chain phosphorylation. Circ Res 2013, 112:1230-1233

9. El-Haroun H, Clarke DL, Deacon K, Bradbury D, Clayton A Sutcliffe A, Knox AJ: IL-1 $\beta$, BK, and TGF- $\beta 1$ attenuate PGI2mediated cAMP formation in human pulmonary artery smooth muscle cells by multiple mechanisms involving p38 MAP kinase and PKA. Am J Physiol Lung Cell Mol Physiol 2008, 294:L553-L562

10. Liu Y, Ren W, Warburton R, Toksoz D, Fanburg BL: Serotonin induces Rho/ROCK-dependent activation of Smads 1/5/8 in pulmonary artery smooth muscle cells. FASEB J 2009, 23:2299-2306

11. Kruzliak P, Maruyama J, Maruyama K: Role of nitric oxide in pathophysiology and treatment of pulmonary hypertension. Vitam Horm 2014, 96:407-424

12. Tabima DM, Frizzell S, Gladwin MT: Reactive oxygen and nitrogen species in pulmonary hypertension. Free Radic Biol Med 2012, 52: 1970-1986

13. Chester AH, Yacoub MH: The role of endothelin-1 in pulmonary arterial hypertension. Glob Cardiol Sci Pract 2014, 2014:62-78

14. Shao D, Park JES, Wort SJ: The role of endothelin-1 in the pathogenesis of pulmonary arterial hypertension. Pharmacol Res 2011, 63: $504-511$

15. Shirai M, Shimouchi A, Ikeda S, Ninomiya I, Sunagawa $K$ Kangawa K, Matsuo H: Vasodilator effects of adrenomedullin on small pulmonary arteries and veins in anaesthetized cats. Br J Pharmacol 1997, 121:679-686

16. Baliga RS, Macallister RJ, Hobbs AJ: Vasoactive peptides and the pathogenesis of pulmonary hypertension: role and potential therapeutic application. Handb Exp Pharmacol 2013, 218:477-511

17. Aggarwal S, Gross CM, Sharma S, Fineman JR, Black SM: Reactive oxygen species in pulmonary vascular remodeling. Compr Physiol 2013, 3:1011-1034

18. Deacon K, Knox AJ: Endothelin-1 (ET-1) increases the expression of remodeling genes in vascular smooth muscle through linked calcium and cAMP pathways: role of a phospholipase $\mathrm{A}(2)(\mathrm{CPLA}(2)) /$ cyclooxygenase-2 (COX-2)/prostacyclin receptordependent autocrine loop. J Biol Chem 2010, 285:25913-25927

19. Matsui H, Shimosawa T, Itakura K, Guanqun X, Ando K, Fujita T: Adrenomedullin can protect against pulmonary vascular remodeling induced by hypoxia. Circulation 2004, 109:2246-2251

20. Sitbon O, Morrell N: Pathways in pulmonary arterial hypertension: the future is here. Eur Respir Rev 2012, 21:321-327 
21. Westphal M, Booke M, Dinh-Xuan AT: Adrenomedullin: a smart road from pheochromocytoma to treatment of pulmonary hypertension. Eur Respir J 2004, 24:518-520

22. Machado RD, Pauciulo MW, Thomson JR, Lane KB, Morgan NV, Wheeler L, Phillips JA 3rd, Newman J, Williams D, Galie N, Manes A, McNeil K, Yacoub M, Mikhail G, Rogers P, Corris P, Humbert M, Donnai D, Martensson G, Tranebjaerg L, Loyd JE, Trembath RC, Nichols WC: BMPR2 haploinsufficiency as the inherited molecular mechanism for primary pulmonary hypertension. Am J Hum Genet 2001, 68:92-102

23. Tuder RM, Voelkel NF: Pulmonary hypertension and inflammation. J Lab Clin Med 1998, 132:16-24

24. Pullamsetti SS, Savai R, Janssen W, Dahal BK, Seeger W, Grimminger F, Ghofrani HA, Weissmann N, Schermuly RT: Inflammation, immunological reaction and role of infection in pulmonary hypertension. Clin Microbiol Infect 2011, 17:7-14

25. Groth A, Vrugt B, Brock M, Speich R, Ulrich S, Huber LC: Inflammatory cytokines in pulmonary hypertension. Respir Res 2014, $15: 47$

26. Dorfmuller P, Zarka V, Durand-Gasselin I, Monti G, Balabanian K, Garcia G, Capron F, Coulomb-Lhermine A, Marfaing-Koka A, Simonneau G, Emilie D, Humbert M: Chemokine RANTES in severe pulmonary arterial hypertension. Am J Respir Crit Care Med 2002, 165:534-539

27. Voelkel NF, Vandivier RW, Tuder RM: Vascular endothelial growth factor in the lung. Am J Physiol Lung Cell Mol Physiol 2006, 290: L209-L221

28. Fagan KA, Morrissey B, Fouty BW, Sato K, Harral JW, Morris KG Jr, Hoedt-Miller M, Vidmar S, McMurtry IF, Rodman DM: Upregulation of nitric oxide synthase in mice with severe hypoxia-induced pulmonary hypertension. Respir Res 2001, 2: 306-313

29. Gielis JF, Lin JY, Wingler K, Van Schil PE, Schmidt HH, Moens AL: Pathogenetic role of eNOS uncoupling in cardiopulmonary disorders. Free Radic Biol Med 2011, 50:765-776

30. Pullamsetti S, Kiss L, Ghofrani HA, Voswinckel R, Haredza P, Klepetko W, Aigner C, Fink L, Muyal JP, Weissmann N, Grimminger F, Seeger W, Schermuly RT: Increased levels and reduced catabolism of asymmetric and symmetric dimethylarginines in pulmonary hypertension. FASEB J 2005, 19:1175-1177

31. Woods M, Mitchell JA, Wood EG, Barker S, Walcot NR, Rees GM, Warner TD: Endothelin-1 is induced by cytokines in human vascular smooth muscle cells: evidence for intracellular endothelin-converting enzyme. Mol Pharmacol 1999, 55:902-909

32. Dschietzig T, Alexiou K, Richter C, Bobzin M, Baumann G, Stangl K, Brunner F: Endotoxin causes pulmonary hypertension by upregulating smooth muscle endothelin type-B receptors: role of aldose reductase. Shock (Augusta, Ga) 2008, 30:189-196

33. Swain SD, Han S, Harmsen A, Shampeny K, Harmsen AG: Pulmonary hypertension can be a sequela of prior Pneumocystis pneumonia. Am J Pathol 2007, 171:790-799

34. Swain SD, Siemsen DW, Pullen RR, Han S: CD4(+) T cells and IFN$\gamma$ are required for the development of Pneumocystis-associated pulmonary hypertension. Am J Pathol 2014, 184:483-493

35. Austin ED, Lahm T, West J, Tofovic SP, Johansen AK, Maclean MR, Alzoubi A, Oka M: Gender, sex hormones and pulmonary hypertension. Pulm Circ 2013, 3:294-314

36. Swain SD, Lee SJ, Nussenzweig MC, Harmsen AG: Absence of the macrophage mannose receptor in mice does not increase susceptibility to Pneumocystis carinii infection in vivo. Infect Immun 2003, 71:6213-6221

37. Held HD, Martin C, Uhlig S: Characterization of airway and vascular responses in murine lungs. Br J Pharmacol 1999, 126:1191-1199

38. Paddenberg R, Konig P, Faulhammer P, Goldenberg A, Pfeil U, Kummer W: Hypoxic vasoconstriction of partial muscular intraacinar pulmonary arteries in murine precision cut lung slices. Respir Res 2006, 7:93
39. Sanderson MJ: Exploring lung physiology in health and disease with lung slices. Pulm Pharmacol Ther 2011, 24:452-465

40. Faro R, Moreno L, Hislop AA, Sturton G, Mitchell JA: Pulmonary endothelium dependent vasodilation emerges after birth in mice. Eur J Pharmacol 2007, 567:240-244

41. Wright JL, Churg A: Short-term exposure to cigarette smoke induces endothelial dysfunction in small intrapulmonary arteries: analysis using guinea pig precision cut lung slices. J Appl Physiol 2008, 104: $1462-1469$

42. Schneider CA, Rasband WS, Eliceiri KW: NIH Image to ImageJ: 25 years of image analysis. Nat Methods 2012, 9:671-675

43. Corraliza IM, Campo ML, Soler G, Modolell M: Determination of arginase activity in macrophages: a micromethod. J Immunol Methods 1994, 174:231-235

44. Meissner N, Swain S, McInnerney K, Han S, Harmsen AG: Type-I IFN signaling suppresses an excessive IFN-gamma response and thus prevents lung damage and chronic inflammation during Pneumocystis (PC) clearance in CD4 T cell-competent mice. Am J Pathol 2010, 176:2806-2818

45. Livak KJ, Schmittgen TD: Analysis of relative gene expression data using real-time quantitative PCR and the 2(-Delta $\mathrm{C}(\mathrm{T}))$ method. Methods 2001, 25:402-408

46. Maarsingh H, Pera T, Meurs H: Arginase and pulmonary diseases. Naunyn Schmiedebergs Arch Pharmacol 2008, 378:171-184

47. Isumi Y, Shoji H, Sugo S, Tochimoto T, Yoshioka M, Kangawa K, Matsuo H, Minamino N: Regulation of adrenomedullin production in rat endothelial cells. Endocrinology 1998, 139:838-846

48. Miller MJ, Martínez A, Unsworth EJ, Thiele CJ, Moody TW, Elsasser T, Cuttitta F: Adrenomedullin expression in human tumor cell lines: its potential role as an autocrine growth factor. J Biol Chem 1996, 271:23345-23351

49. De Kimpe SJ, Van Heuven-Nolsen D, van Amsterdam JG, Radomski MW, Nijkamp FP: Induction of nitric oxide release by interferon-gamma inhibits vasodilation and cyclic GMP increase in bovine isolated mesenteric arteries. J Pharmacol Exp Ther 1994, 268 : 910-915

50. Koh KP, Wang Y, Yi T, Shiao SL, Lorber MI, Sessa WC, Tellides G, Pober JS: T cell-mediated vascular dysfunction of human allografts results from IFN-gamma dysregulation of NO synthase. J Clin Invest 2004, 114:846-856

51. Wort SJ, Ito M, Chou P-C, Mc Master SK, Badiger R, Jazrawi E, de Souza P, Evans TW, Mitchell JA, Pinhu L, Ito K, Adcock IM: Synergistic induction of endothelin-1 by tumor necrosis factor alpha and interferon gamma is due to enhanced NF-kappaB binding and histone acetylation at specific kappaB sites. J Biol Chem 2009, 284: 24297-24305

52. George PM, Badiger R, Shao D, Edwards MR, Wort SJ, Paul-Clark MJ, Mitchell JA: Viral Toll like receptor activation of pulmonary vascular smooth muscle cells results in endothelin-1 generation; relevance to pathogenesis of pulmonary arterial hypertension. Biochem Biophys Res Commun 2012, 426:486-491

53. Chrobak I, Lenna S, Stawski L, Trojanowska M: Interferon- $\gamma$ promotes vascular remodeling in human microvascular endothelial cells by upregulating endothelin (ET)-1 and transforming growth factor (TGF) $\beta 2$. J Cell Physiol 2013, 228:1774-1783

54. Allahdadi KJ, Walker BR, Kanagy NL: Augmented endothelin vasoconstriction in intermittent hypoxia-induced hypertension. Hypertension 2005, 45:705-709

55. Wang Z, Li A-Y, Guo Q-H, Zhang J-P, An Q, Guo Y-J, Chu L, Weiss JW, Ji E-S: Effects of cyclic intermittent hypoxia on ET-1 responsiveness and endothelial dysfunction of pulmonary arteries in rats. PLoS One 2013, 8:e58078

56. Martínez-Revelles S, Caracuel L, Márquez-Martín A, Dantas A, Oliver E, D'Ocon P, Vila E: Increased endothelin-1 vasoconstriction in mesenteric resistance arteries after superior mesenteric ischaemiareperfusion. Br J Pharmacol 2012, 165:937-950 
57. Lin Y-J, Kwok C-F, Juan C-C, Hsu Y-P, Shih K-C, Chen C-C, Ho L-T: Angiotensin II enhances endothelin-1-induced vasoconstriction through upregulating endothelin type A receptor. Biochem Biophys Res Commun 2014, 451:263-269

58. Matsumoto G, Nakagawa NK, Vieira RP, Mauad T, da Silva LFF, de André CD, Carvalho-Oliveira R, Saldiva PH, Garcia ML: The time course of vasoconstriction and endothelin receptor A expression in pulmonary arterioles of mice continuously exposed to ambient urban levels of air pollution. Environ Res 2010, 110:237-243

59. Henno P, Boitiaux J-F, Douvry B, Cazes A, Lévy M, Devillier P, Delclaux C, Israël-Biet D: Tobacco-associated pulmonary vascular dysfunction in smokers: role of the ET-1 pathway. Am J Physiol Lung Cell Mol Physiol 2011, 300:L831-L839

60. Murakami S, Kimura H, Kangawa K, Nagaya N: Physiological significance and therapeutic potential of adrenomedullin in pulmonary hypertension. Cardiovasc Hematol Disord Drug Targets 2006, 6: $125-132$

61. Delgado M, Ganea D: Anti-inflammatory neuropeptides: a new class of endogenous immunoregulatory agents. Brain Behav Immun 2008, 22:1146-1151

62. Al Shuaibi M, Bahu RR, Chaftari AM, Al Wohoush I, Shomali W, Jiang Y, Debiane L, Raad S, Jabbour J, Al Akhrass F, Hachem RY,
Raad I: Pro-adrenomedullin as a novel biomarker for predicting infections and response to antimicrobials in febrile patients with hematologic malignancies. Clin Infect Dis 2013, 56:943-950

63. Sugo S, Minamino N, Shoji H, Kangawa K, Kitamura K, Eto T, Matsuo H: Interleukin-1, tumor necrosis factor and lipopolysaccharide additively stimulate production of adrenomedullin in vascular smooth muscle cells. Biochem Biophys Res Commun 1995, 207: $25-32$

64. Kapas S, Tenchini ML, Farthing PM: Regulation of adrenomedullin secretion in cultured human skin and oral keratinocytes. J Invest Dermatol 2001, 117:353-359

65. Kuchinke W, Hart RP, Jonakait GM: Identification of mRNAs regulated by interferon-gamma in cultured rat astrocytes by PCR differential display. Neuroimmunomodulation 1995, 2: 347-355

66. Udono T, Takahashi K, Nakayama M, Murakami O, Durlu YK, Tamai M, Shibahara S: Adrenomedullin in cultured human retinal pigment epithelial cells. Invest Ophthalmol Vis Sci 2000, 41: 1962-1970

67. Didierlaurent A, Goulding J, Hussell T: The impact of successive infections on the lung microenvironment. Immunology 2007, 122: 457-465 